\title{
ANALISIS EFEKTIVITAS PEMASARAN PUSAT KEGIATAN BELAJAR MASYARAKAT MASA DEPAN CERAH BANDUNG MENGGUNAKAN ANALISIS SWOT
}

\author{
Gawik Setiawan $^{1}$, Hesti Siti Nurbarkah ${ }^{2}$, Ikhsan Nugraha ${ }^{3}$, Ipan Solihin ${ }^{4}$, Iyan \\ Sopyan $^{5}$, Dewi Kurniasari ${ }^{6}$ \\ 1,2,3,4,5,6 Universitas Islam Negeri Sunan Gunung Djati Bandung \\ Email:info@,uinsgd.ac.id
}

\begin{abstract}
Abstrak
Jurnal ini menjelaskan kontribusi pendidikan nonformal terhadap pembangunan di Indonesia. Pendidikan nonformal dalam jurnal ini adalah Pusat Kegiatan Belajar Masyarakat. Sebagai salah satu wadah dalam melaksanakan pendidikan untuk memenuhi kebutuhan masyarakatnya akan pentingnya pendidikan, pemerintah mendukung berlangsungnya Pusat Kegiatan Belajar Masyarakat secara penuh melalui Kemendikbud. Penelitian ini menggunakan metode kualitatif dengan memanfaatkan data dari perusahaan, buku, artikel, internet dan pendapat dari ahli dalam bidang terkait yang sesuai dengan pembahasan. Penelitian ini bertujuan untuk menilai efektivitas pemasaran yang dilakukan PKBM MDC Bandung pada tahun 2018-2020 dengan menggunakan analisis SWOT (Strenght, Weakness, Oportunities, Threats)
\end{abstract}

Kata kunci: PKBM, Efektivitas, SWOT, Pendidikan Nonformal

\section{Abstract}

This journal describes the contribution of non-formal education to development in Indonesia. Non-formal education in this journal is the Center for Community learning activities. As one of the containers in conducting education to meet the needs of the community in the importance of education, the Government supports the full community learning activities Center through Kemendikbud. This research uses qualitative methods by utilizing data from companies, books, articles, the Internet and opinions of experts in related fields in accordance with the discussion. This research aims to assess the marketing effectiveness conducted by PKBM MDC Bandung in 2018-2020 by using SWOT analysis

Keyword: PKBM. Efektiveness, SWOT, Non-formal Education

\section{A. PENDAHULUAN}

Lembaga pendidikan adalah lembaga atau tempat berlangsungnya proses pendidikan atau belajar mengajar yang dilakukan dengan tujuan untuk mengubah tingkah laku individu menuju ke arah yang lebih baik melalui interaksi dengan lingkungan sekitar. ${ }^{1}$

\footnotetext{
${ }^{1}$ Bitar, "Lembaga Pendidikan", Seputar Ilmu, diakses dari https://seputarilmu.com/2019/02/lembagapendidikan.html pada 21 juli 2020, pukul 10.14
} 


\section{ARTIKEL}

lembaga pendidikan merupakan suatu tempat atau wadah dimana proses pendidikan berlangsung yang dilaksanakan dengan sebuah tujuan untuk mengubah tingkah laku seseorang kearah yang lebih baik melalui sebuah interaksi dengan lingkungan sekitar serta wawasan dan pengetahuan yang didapat. Lingkungan pendidikan antara lain pendidikan formal (sekolah), informal (keluarga) dan non formal (masyarakat). Lingkungan pendidikan itu sangat penting dalam suatu proses pendidikan karena fungsinya sangat menunjang Proses Belajar Mengajar yang tertib dan nyaman. Lembaga pendidikan menjadi wadah pencetak generasi bangsa yang fundamental. Suatu bangsa dinilai maju apabila tingkat pendidikan warganya baik, cerminan kualitas sumberdaya manusis dilinlai dari tingkat pendidikannya.

Berbagai lembaga pendidikan di Indonesia hadir sebagai solusi bagi peningkatan kualitas pendidikan warga negara. Lembaga pendidikan Negeri dan Swasta pun semakin dicari oleh masyarakat. Keadaan ekonomi dan geografis menjadi stimulus bagi pengembangan pendidikan swasta terutama lembaga pendidikan non formal yang memiliki program kelompok belajar paket, seperti paket $\mathrm{A}$, paket $\mathrm{B}$, dan paket $\mathrm{C}$, juga ada beberapa homeschooling, kursus bahasa inggris dan kursus komputer perakantoran serta bimbingan belajar guna menciptakan dan memberikan pendidikan yang layak dan berkualitas bagi seluruh masyarakat.

PKBM adalah suatu wadah berbagai kegiatan pembelajaran di masyarakat yang diarahkan untuk pemberdayaan potensi dalam menggerakkan pembangunan di bidang sosial, ekonomi, dan budaya ${ }^{2}$. Pembentukan PKBM bertujuan untuk memperluas kesempatan masyarakat, khususnya masyarakat yang tidak mampu untuk melanjutkan usahanya dalam meningkatkan pengetahuan, keterampilan dan sikap mental untuk pengembangan diri secara mandiri yang akhirnya berdampak pada meningkatnya taraf ekonomi.

PKBM memiliki tugas pokok untuk memberikan kemudahan bagi masyarakat khususnya masyarakat kurang mampu untuk mengembangkan diri melalui penyelenggaraan pendidikan luar sekolah. Sesuai dengan Undang-undang Nomor 20 Tahun 2003 tentang Sistem Pendidikan Nasional pasal 1 ayat 12 menyatakan bahwa pendidikan nonformal merupakan jalur pendidikan diluar pendidikan formal yang pelaksanaanya secara terstruktur dan berjenjang. Pendidikan nonformal dapat berfungsi sebagai pelengkap, penambah dan sebagai lembaga lain yang berdiri sendiri substitutive

\footnotetext{
${ }^{2}$ Kemdikbud, 2017; Engchun, dkk., 2018
} 
ARTIKEL

Bandung adalah salah satu kota dengan tingkat persaingan usaha yang tinggi, termasuk lembaga - lembaga pendidikan nonformal yang bersaing mendapatkan kepercayaan serta loyalitas dari para pengguna jasa tersebut. Beragamnya jenis jasa pendidikan menandakan bahwa permintaan terhadap lembaga pendidikan di Kota Bandung sangat besar. Di sisi lain, banyaknya anak muda yang hidup dengan keterbatasan ekonomi menyebabkan kesenjangan dalam strata ekonomi dan pendidikan, banyak anak putus sekolah dan memilih untuk bekerja membantu orang tua karena keterbatasan ekonomi yang berakibat pada terputusnya rantai pendidikan yang harusnya diterima anak tersebut. Peluang yang terbuka lebar bagi lembaga-lembaga pendidikan swasta nonformal dengan program kelompok belajar paket dan homeschooling.

Pusat Kegiatan Belajar Masyarakat Masa Depan Cerah (PKBM MDC) merupakan salah satu Lembaga Pendidikan Non Formal di Kota Bandung Jawa Barat yang menyelenggarakan Program Pendidikan Paket A setara dengan SD, Paket B setara dengan SMP, serta paket C yang setara dengan SMA dan juga program keahlian khusus Bahasa Inggris dan Kursus Komputer serta homeschooling.

Dalam mengahadapi persaingan mendapatkan pelanggan atau pengguna jasa pendidikan, perusahaan atau lembaga harus mampu mengetahui titik kelebihan dan kekurangannya sebagai landasan dasar dalam perumusan strategi lembaga, khususnya dalam strategi pemasaran dengan tujuan untuk meningkatkan efektivitas pemasaran atas nilai produk dan image brand lembaga. Analisis SWOT memberikan gambaran kelemahan dan kelebihan dari lembaga, sehingga sangat membantu dalam merumuskan strategi yang akan digunakan oleh lembaga.

\section{B. KAJIAN PUSTAKA}

Menurut Kotler dan Keller, pemasaran adalah mengidentifikasi dan memenuhi kebutuhan manusia dan sosial, salah satu definisi yang baik dan singkat dari pemasaran adalah "memenuhi kebutuhan dengan cara yang menguntungkan". ${ }^{3}$

Menurut America Marketing Association (AMA) yang dikutip Kotler dan Keller, pemasaran adalah fungsi organisasi dan serangkaian untuk mennciptakan, mengkomunikasikan, dan memberi nilai kepada pelanggan dan untuk mengola hubungan pelanggan dengan cara menguntungkan organisasi dan pemangku kepentingan.

\footnotetext{
${ }^{3}$ Kotler dan Keller. 2007.
} 
Menurut Rangkuti (2006) mengemukakan bahwa SWOT adalah singkatan dari lingkungan internal stregtht dan weaknesses serta lingkungan eksternal Opportunities dan Threats yang dihadapi dunia bisnis. Analisis SWOT membandingkan antara faktor eksternal Peluang (Opportunities) dan Ancaman (Threats) dengan faktor internal kekuatan (Strengths) dengan kelemahan (Weaknesses). ${ }^{4}$

Sedangkan Kotler (2002) mengemukakan bahwa analisis SWOT adalah evaluasi terhadap keseluruhan kekuatan, kelemahan, peluang dan ancaman disebut analisis SWOT. ${ }^{5}$

Yang dimaksud dengan Strategi pemasaran menurut William J. Stanton dalam Basu Swasta adalah suatu sistem keseluruhan dari kegiatan- kegiatan perusahaan yang terdiri dari tujuan untuk merencanakan, menentukan harga, mempromosikan dan mendistribusikan barang serta jasa yang dapat memuaskan kebutuhan baik kepada pembeli yang ada maupun pembeli potensial. ${ }^{6}$

Analisis SWOT digunakan untuk melihat kekuatan, kelemahan, peluang dan ancaman yang akan dihadapi oleh perusahaan. Dengan melihat kekuatan yang dimiliki serta mengembangkan kekuatan tersebut dipastikan bahwa perusahaan akan lebih maju dibanding pesaing yang ada. Demikian juga dengan kelemahan yang dimiki harus diperbaiki agar perusahaan bisa eksis. Peluang yang harus dimanfaatkan sebaik-baiknya oleh perusahaan agar volume penjualan dapat meningkat, dan ancaman yang akan dihadapi oleh perusahaan haruslah dihadapi dengan mengembangkan strategi pemasaran yang baik.

\section{PENELITIAN TERDAHULU}

Evaluasi manajemen pemasaran jasa pendidikan nonformal di PKBM Kota Salatiga penting dilakukan ${ }^{7}$, mengingat kebutuhan dan animo masyarakat semakin meningkat yang dapat dilihat dari peningkatan jumlah peserta didik di PKBM dalam kurun waktu 2016 s.d. 2019 mengalami kenaikan grafik yang signifkan

Dalam perkembangan pemasaran memunculkan sesuatu yang baru, khususnya dalam hal pelayanan dan fasilitas ${ }^{8}$

Berbeda dengan Anwar (2014) hasil penelitiannya menunjukkan bahwa strategi pemasaran jasa pendidikan yang dilakukan untuk meningkatkan peminat layanan jasa

\footnotetext{
${ }^{4}$ Rangkuti. 2006

${ }^{5}$ Kotler. 2002

${ }^{6}$ William J. Stanton. 2000

7 Hasthanti, 2018; Nugroho, 2013; Ridwan, 2017

${ }^{8}$ Ružinská, 2018; Sunyoto \& Susanti, 2015
} 
pendidikan menggunakan pemasaran secara langsung dan marketing tidak langsung lewat optimalisasi kegiatan madrasah. ${ }^{9}$

Fathonah (2016) menyimpulkan peningkatan jumlah siswa menggunakan strategi pemasaran jasa pendidikan. ${ }^{10}$

Penelitian Setiowati (2016) menyimpulkan pemasaran yang didasarkan pada semakin bertambahnya siswa SD Kristen YSKI yang tidak melanjutkan ke SMP Kristen YSKI selama lima tahun terakhir. ${ }^{11}$

\section{METODE PENELITIAN}

Penelitian terhadap efektivitas pemasaran yang dilakukan oleh PKBM MDC Bandung ini merupakan penelitian pustaka (library research) dengan data dan analisis kualitatif $^{12}$. Metode penelitian yang digunakan dalam penelitian ini adalah menggunakan kajian pustaka yaitu dengan menggunakan data dari perusahaan, buku, artikel, internet dan pendapat dari ahli dalam bidang terkait yang sesuai dengan pembahasan. Penelitian ini juga mencari referensi melalui teori yang relevan sesuai dengan permasalahan yang diteliti.

\section{E. HASIL DAN PEMBAHASAN}

Evaluasi umum pemasaran jasa pendidikan PKBM MDC Bandung. Tujuan utama dari pemberdayaan sebagai upaya untuk pembelajaran masyarakat dalam mengentaskan kemiskinan yang berprinsip pada pengembangan dalam perwujudan demokrasi bidang pendidikan. Kegiatan tersebut untuk:

(1) memberdayakan masyarakat agar mampu mandiri (berdaya);

(2) meningkatkan kualitas hidup masyarakat dari segi sosial ekonomi;

(3) meningkatkan kepekaan terhadap masalah-masalah yang terjadi dilingkungan untuk mampu memecahkan segala persoalan.

Evaluasi sasaran atau tujuan pemasaran PKBM. Pemasaran yang dilakukan oleh manajerial (pengelola) dan penanggung jawab program terlebih dahulu mengenal dan memahami: what, who, where, when, why, dan how peluang yang ada pada calon konsumen/pelanggan yaitu masyarakat. Masyarakat yang bermasalah dari berbagai latar belakang sosial, pendidikan, ekonomi, budaya, dan lain sebagainya untuk kembali

\footnotetext{
${ }^{9}$ Anwar, 2014

${ }^{10}$ Ružinská, 2018; Sunyoto \& Susanti, 2015

${ }^{11}$ Setiowati, 2016

${ }^{12}$ Moloeng,1999
} 
ARTIKEL

bersekolah dan mengenyam serta mendapatkan pendidikan dengan jalur pendidikan nonformal PKBM.

Evaluasi Perilaku konsumen PKBM MDC Bandung. Adanya penurunan jumlah peserta didik dari tahun 2018 sampai dengan tahun 2020 sesuai data yang diberikan oleh pihak PKBM MDC Bandung, lebih tepatnya yaitu mulai bulan juli 2018-juni 2019 dan juli 2019-juni 2020. Berikut disajikan tabel data jumlah pendaftar pada PKBM MDC Bandung:

\begin{tabular}{|c|c|c|}
\hline Referensi/Tahun & Juli 2018 - Juli 2019 & Juli 2019 - Juni 2020 \\
\hline Online & 283 siswa & 186 siswa \\
\hline Offline & 334 siswa & 157 siswa \\
\hline Jumlah siswa & 617 siswa & 343 siswa \\
\hline
\end{tabular}

Tabel 1.0 Jumlah pendaftar PKBM MDC Bandung

Dari data dalam tabel di atas bisa kita simpulkan bahwa pendaftar pada tahun ajaran 2018-2019 lebih banyak daripada tahun berikutnya yaitu tahun 2019-2020, menjadi sebuah pertanyaan, apakah ini dipengaruhi oleh strategi pemasaran yang dilakukan kurang efektif? Ataukah ada faktor lain yang menpengaruhi turunnya pendaftar tahun pada tahun 2020 ?. Beberapa faktor yang mungkin mempunyai pengaruh terhadap turunnya pendaftar pada tahun ini adalah:

(1) strategi pemasaran yang kurang efektif;

(2) turunnya tingkat kepercayaan masyarakat terhadap PKBM;

(2) menurunnya angka siswa putus sekolah formal;

(3) dan yang mungkin paling rasional adalah adanya pandemic Covid-19 di tahun 2020.

Evaluasi menggunakan analisis SWOT untuk menilai efektivitas pemasaran yang dilakukan oleh PKBM MDC Bandung dari Juli 2018 - Juni 2020.

Analisis SWOT adalah sebuah teknik perencanaan strategis yang berguna untuk menilai kekuatan dan kelemahan, peluang dan ancaman yang terdapat di suatu perusahaan, baik itu dalam perencanaan saat ini ataupun yang baru. ${ }^{13}$

Analisis SWOT pertama kali diperkenalkan oleh Albert S. Humphrey pada tahun 1960-an, yang saat itu ia sedang memimpin sebuah proyek penelitian di Stanford Research

\footnotetext{
${ }^{13}$ Ulia Kumalasari, “Analisis SWOT”, rumus.co.id, diakses dari https://rumus.co.id/analisis-swot/, pada 17 Juli 2020, pukul 18.58
} 
Institute dengan menggunakan data dari perusahaan-perusahaan Fortune 500.

Tujuan dari penggunaan metode analisis ini adalah untuk menggambarkan situasi serta kondisi yang tengah dihadapi oleh seseorang untuk membandingkan, daripada mengembangkan alat analisis yang dapat digunakan untuk menemukan solusi untuk masalah yang dimaksud. Analisis SWOT sendiri merupakan akronim dari (Strenght, Weakness, Oportunities, dan Threats

Kekuatan (Strenght)

Berikut analisis kekuatan (Strenght) pada PKBM MDC Bandung

Yang menjadi kekuatan dari PKBM MDC adalah:

1. Citra baik yang terbentuk di masyarakat

2. Memiliki 3 cabang di seluruh Kota Bandung

3. Menjadi PKBM yang memiliki jumlah siswa terbanyak se Kota Bandung

4. Dengan biaya paling terjangkau diantara PKBM lain

5. Pembelajaran yang dilaksanakan di PKBM sesuai dengan kurikulum standar pemerintah yang telah ditetapkan

6. Ijazah yang dikeluarkan oleh PKBM MDC merupakan ijazah resmi

7. Setiap pertemuan dalam pembelajaran mendapatkan buku dan modul latihan serta modul pelajaran secara gratis.

8. Banyak lulusan PKBM MDC yang diterima di perguruan tinggi ternama di Indonesia dan diterima bekerja di perusahaan nasional

9. Dengan waktu pembelajaran yang fleksibel, sehingga memudahkan siswa memilih sendiri jadwalnya

10. Adanya kerjasama dengan pemerintah, sehingga memudahkan siwa membayar biaya pendidikan dengan adanya SKTM

Kelemahan (Weakness)

Berikut analisis kelemahan (weakness) pada PKBM MDC Bandung

1. Belum menggunakan manajemen secara terpadu

2. Bagian-bagian maupun divisi-divisi belum sepenuhnya tertata dengan baik

3. Tupoksi dan jobdes yang belum dirinci secara jelas

4. Fasilitas yang masih belum cukup memadai

5. Kurangnya fasilitas bagi murid untuk mengembangkan potensi diri

6. Relasi yang kurang

7. Akreditasi masih $\mathrm{C}$ 
Peluang (Oportunities)

Berikut analisis peluang (Oportunities) pada PKBM MDC Bandung

1. Banyaknya pesaing yang belum bekerjasama dengan pemerintah

2. Meningkatnya penggunaan teknologi informasi, sehingga memudahkan informasi PKBM menjangkau masyarakat lebih luas lagi

3. Lulusan yang banyak dibutuhkan dalam dunia kerja

Ancaman (Threats)

Berikut analisis ancaman (Threats) pada PKBM MDC Bandung

1. Banyaknya pesaing sejenis

2. Maraknya homeschooling yang lebih memiliki nilai

3. Ancaman pesaing yang memiliki fasilitas yang lebih baik

Pelaksanaan strategi manajemen pemasaran yaitu strategi 4P (Product, Place, Price, Promotion) pemasaran jasa Pendidikan Nonformal yang dilakukan PKBM MDC Bandung yaitu: (1) memiliki product berupa Program Paket A, B, C, memiliki program keahlian kursus bahas inggris dan komputer perkantoran, memiliki home schooling.

Pada dasarnya pengelola sudah melakukan analisis dan strategi bauran pemasaran. Dari telaah 4P ternyata banyak keragaman yang dilakukan oleh PKBM MDC dalam menarik minat calon pelanggan untuk mendaftar, berikut analisis dari bauran pemasaran 4P: Product

Dari penyelenggaraan program layanan berupa Pendidikan Kesetaraan Paket A/B/C, Pendidikan Kesetaraan Paket A/B/C inklusi, Homeschooling, dan lain-lain.

Price

Penentuan biaya bulanan (Sumbangan Pembinaan Pendidikan / SPP) sangat kompetitif, Harga yang ditetapkan oleh PKBM MDC untuk Program yang telah ditentukan adalah yang paling murah diantaranya yaitu ada 2 pilihan: (1) Rp. 290.000,-/bulan, selama 7 kali angsuran, Total Rp.2.030.000,-; (2) Rp. 190.000,-/bulan, selama 12 kali angsuran, Total Rp.2.280.000, bahkan ada yang menggratiskan SPP dengan menggunakan SKTM.

\section{Promotion}

Kegiatan promosi (promotion) dilakukan dengan berbagai macam cara, yaitu dengan word to mouth, pendekatan persuasive ke kehidupan sosial kemasyarakatan, publikasi medsos website, IG, Facebook, menggunakan brosur/leaflet.

Place

Tempat untuk beraktivitas di gedung sendiri, PKBM MDC sudah memiliki 3 gedung 


\section{ARTIKEL}

yang dapat digunakan untuk kegiatan belajar mengajar, yang pertama adalah di Jl Soekarno Hatta no.18 Bandung, kedua ada di Jl. Sekelimus Barat No. 49 (Belakang Apartemen Newton), dan yang terbaru ada di Jl. Terusan Gatot subroto No. 340 (Prapatan Binong, arah PINDAD).

Masyarakat (PKBM) sebagai salah satu lembaga penyelenggara satuan pendidikan luar sekolah (PLS) yang bervisi untuk pemberdayaan masyarakat dalam rangka meningkatkan kualitas hidupnya. Penyelenggara pendidikan nonformal dituntut agar lebih kreatif dan inovatif dalam menggali keunikan dan keunggulan lembaganya agar semakin diminati serta dipercaya masyarakat sebagai pengguna jasa pendidikan nonformal. Untuk mempertahankan eksistensi, keberlangsungan dan kesinambungan program-program yang ada di PKBM MDC Bandung, maka sangat perlu adanya evaluasi efektivitas pemasaran jasa pendidikan non formal di PKBM MDC Bandung. Peran PKBM di masyarakat sebagai sebuah solusi dalam persoalan-persoalan pendidikan yang terjadi hari ini.

\section{F. KESIMPULAN}

Pemerintah Indonesia telah berkomitmen untuk terus melaksanakan pembangunan secara berkelanjutan sesuai dengan SDGs (Sustainable Development Goals), SDGs merupakan sebuah program pembangunan berkelanjutan dimana didalamnya terdapat 17 tujuan dengan 169 target yang terukur dengan tenggat waktu yang ditentukan.

Pembangunan harus merata ke seluruh pelosok Indonesia. Pembangunan sarana infrastruktur merupakan suatu kewajiban bagi negara yang bertujuan menyejahterakan rakyat. Pembangunan harus dapat dinikmati oleh seluruh lapisan masyarakat agar tidak terjadi ketimpangan pendidikan, sosial dan ekonomi antar wilayah. Salah satu unsur dalam kesuksesan pembangunan adalah tingkat pendidikan yang didapat masyarakatnya.

Pendidikan merupakan salah satu jalan mensukseskan pembangunan, dengan sumberdaya manusia yang terdidik, maka pembangunan yang merata dapat terlaksana dengan baik. Pendidikan formal dan pendidikan nonformal menjadi kunci dalam suksesnya pembangunan yang dicanangkan pemerintah, pendidikan formal dengan kurikulum terpadunya, dan pendidikan nonformal dengan fleksibilitas serta penggunaan waktu yang efisien, maka dari itu, jika pendidikan terus diperhatikan keberlangsungannya dan terus diberikan perbaikan-perbaikan, bukan tidak mungkin jika indonesia emas 2045 adalah benar-benar era kejayaan.

PKBM MDC hadir sebagai solusi atas kurangnya akan pendidikan untuk masyarakat 
ARTIKEL

yang kurang mampu dan putus sekolah. Dalam memberikan pelayanan yang terbaik, maka pendidikan nonformal pun harus melakukan evaluasi serta analisis terhadap kinerja lembaga tersebut.

Hasil evaluasi diatas menunjukkan bahwa pelaksanaan manajemen pemasaran jasa diukur dari efektivitas pemasaran yang dilakukan pendidikan Nonformal di Pusat Kegiatan Belajar Masyarakat Masa Depan Cerah (PKBM MDC) Kota Bandung sudah dilakukan dengan menerapkan seluruh bauran pemasaran 4P. Sejauh dari analisis diatas bisa kita simpulkan bahwa keunggulan dari PKBM MDC Bandung adalah terletak pada harga yang kompetitif, citra yang bagus, mudahnya dalam sistem pembayaran, dan PKBM MDC adalah yang terbesar di Kota Bandung.

Menurut penulis, ada beberapa hal yang disarankan, yaitu: Bagi pemerintah, perlu disediakan dan lebih diperhatikan lagi dari sebelumnya tentang pendidikan nonformal ini agar cita-cita warga negara mendapatkan pendidikan yang layak dapat terpenuhi. Bagi PKBM, perlu adanya sistem pemasaran terpadu agar lebih efektif dan tepat sasaran dalam memasarkan produk jasanya.

\section{DAFTAR PUSTAKA}

Alma, B. (2009). Manajemen Pemasaran dan Pemasaran Jasa. Bandung: Alfabet

Anwar, D. (2014). Strategi Pemasaran Jasa Pendidikan dalam Meningkatkan Peminat Layanan Pendidikan di Madrasah Mualimin Muhammadiyah Yogyakarta. (http://digilib.uin-suka.ac.id)

Arikunto, S. (2011). Evaluasi Program Pendidikan: Pedoman Teoritis Praktis Bagi Mahasiswa dan Praktisi Pendidikan. Jakarta: PT Bumi Aksara.

Assauri, Sofjan. 2013. Manajemen Pemasaran Dasar, Konsep, dan Strategi. Edisi Pertama. Jakarta: Raja Grafindo Persada.

Bitar, Lembaga Pendidikan, Seputar Ilmu. (https://seputarilmu.com/2019/02/lembagapendidikan.html)

Budi, H \& Ismanto, B, (2020), Jurnal Manajemen dan Supervisi Pendidikan : Evaluasi Manajemen Pemasaran Jasa Pendidikan Nonformal Pusat Kegiatan Belajar Masyarakat, Vol 4, 2541-4429.

Faisal, Y. (2015). Manajemen Pemasaran Jasa Pendidikan di Lembaga Kursus dan Pelatihan Bugs Training Center Sleman. Yogyakarta: Universitas Negeri Yogyakarta.

Fathonah, K. (2016). Strategi Pemasaran Jasa Pendidikan dalam Meningkatkan Pelayanan Pendidikan di MAN I Sragen. (http://eprints.iain-surakarta.ac.id)

Kamil, M. (2011). Pendidikan Nonformal. Bandung: Alfabeta. 
ARTIKEL

Kemdikbud. (2017). Model Unggulan Pendidikan Masyarakat. Jakarta: Dirjen Paud dan Dikmas, Kemdikbud

Kotler dan Keller. 2007. Manajemen Pemasaran. Edisi Kedua Belas. Jilid 1.Jakarta: Indeks.

PKBM MDC, (http://paketcbandung.com/)

Ružinská, E. 2018. The Analysis of Selected Aspects of Marketing in Educational Institution. (http://www.mladaveda.sk)

Setiowati, D. (2016). Strategi Bauran Pemasaran Jasa Sekolah (Studi Kasus the Lost Customer SMP Kristen YSKI Semarang). (http://repository.unika.ac.id).

Sunyoto, D., \& Susanti, F. E. (2015). Manajemen Pemasaran Jasa. Yogyakarta: CAPS.

Undang - Undang No.19 Tahun 2008

Undang-undang Nomor 20 Tahun 2003 tentang Sistem Pendidikan Nasional. 2013. Jakarta: Fokus Media. 